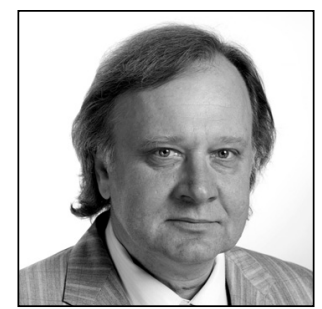

Hannes Veinla

\title{
Which Adverse Environmental Impacts of an Economic Activity Are Legally Acceptable and on What Conditions
}

\section{Introduction}

A fairly clear differentiation between environmental risks and hazards, in combination with the corresponding legal principles, is characteristic of Estonian law. This differentiation is not as clear in many other jurisdictions, including that of EU law. Additionally, relevant literature presents diverging perspectives on the relationship between the precautionary principle and the prevention principle. For instance, L. Krämer does not differentiate between these two principles and considers them to be interchangeable. ${ }^{{ }^{1}}$ E. Rehbinder and N. de Sadeleer, in contrast, see distinct differences between these concepts, a stance that is characteristic of the German legal tradition. In German law, the prevention principle (Prävention) is applied to situations in which there is a known hazard (Gefahr) and the precautionary principle to situations that involve a possible hazard (Risiko) ${ }^{*_{2}}$. In addition to making this distinction, German law specifies the class of risks that need to be tolerated (Restrisiko) - that is, risks against which it is not justified to take measures. Estonian environmental law implements principles similar to those found in German law.

The internationally recognised principles of environmental policy are based on ecosystem services theory, which emphasises the economic benefits related to the ecosystems crucial to human existence. Focusing on ecosystem services provides a way to evaluate the importance and benefits of natural systems and the reasons for protecting natural resources from an economic point of view while also considering the possible economic consequences of not protecting the environment. ${ }^{*}$

This article is motivated by current public discussions in Estonia about several plans for building and development with significant environmental consequences. It appears that the understanding of the economic value of nature is rather one-sided in these discussions. A specific example would be the plan to build a large pulp mill near the river Emajõgi, which has provoked a number of - highly varied - responses, including several scientific interpretations.

\footnotetext{
See. L. Krämer. EC Environmental Law. London: Sweet and Maxwell 2003, on p. 23.

2 See E. Rehbinder. The precautionary principle in an environmental perspective. - E.M. Basse (ed.). Miljørettens grundsporgsmäl. 1994, pp. 91-105, on p. 92; N. de Sadeleer. Environmental Principles: From Political Slogans to Legal Rules. Oxford University Press 2002, on p. 125; K. Pape, K. Schillhorn. Environmental law in the Federal Republic of Germany. N. Koeman (ed.). Environmental Law in Europe. Kluwer Law International 1999, on p. 275.

3 See G.C. Daily, P.A. Matson. Ecosystem services: From theory to implementation. - PNAS 105 (2008) / 28 (15 July). Available at http://www.pnas.org/content/105/28/9455.full (most recently accessed on 25 June 2018).
} 
The analysis proffered in relation to the economic profitability of the proposed pulp mill emphasises the great social and economic benefits of the project. On the other hand, many are very worried about the consequences of the project. The local authorities seem to number among these. For example, Tartu County has cited as a matter of concern the increased consumption of water to be created by the mill's operations. Another concern is whether supplying the mill with large amounts of raw materials could result in exhausting our natural resources (principally forests) or, framed in another way, a decrease in the ecosystem services of the forests. ${ }^{*} 4$

It is important to mention also that the developers of the mill do not seem to be irresponsible and, in fact, have expressed a strong interest in cultivating meaningful, well-founded, and fact-based discussions of the possibility of constructing the mill in Estonia throughout the research and analysis phase. According to the developers, the mill cannot be built until a thorough and transparent process of applying for a planning and environmental permit has been completed and the environmental effects of the mill have been ascertained to be acceptable.

The case of the pulp mill is quite typical of a type of situation that arises frequently in various countries, in which economic interests clash with interests related to protection of the environment and the environmental rights of individuals. Very often, there is direct conflict between these sets of values. In the case of the pulp mill and other, similar projects, the key question that arises is which of the resulting environmental impacts are acceptable and which are not. It must be noted that the probability of an environmental impact and the importance of the consequences of that impact are separate concepts: There are adverse impacts with serious and highly probable consequences but also adverse impacts with equally serious improbable consequences. Additionally, some impacts entail possible consequences that, while very likely to arise, are not very serious. In connection with this distinction, it is important also that the environmental field encompasses many situations for which the level of scientific uncertainty involved must be taken into account. It is evident that these various situations must be considered differently and that the respective legal consequences need to be differentiated.

In evaluation of an environmental impact's acceptability, it must be remembered that the aim behind environmental regulations is not only the preservation of the physical, chemical, biological, and aesthetic qualities of the natural environment but also the protection of the physical, mental, and material rights and interests of individuals. The latter is perhaps even more important than the former, since these interest are often dependent on the environmental conditions, ${ }^{*} 5$ and impact on human interests is another way in which environmental impacts are manifested. ${ }^{* 6}$ Regrettably, this recognition is often forgotten in practice, with the realm of environmental law frequently seeing the issue mistakenly reduced to one of mere nature conservation law.

This article focuses on the most important economic, social, and environmental considerations affecting legal criteria and mechanisms from the standpoint of environmental law. In the following analysis, issues have been analysed particularly in the context of Estonian environmental law - namely, the General Part of the Environmental Code Act.

Since environmental regulations are very extensive and, at times, very particular, this paper does not delve into the details. It gives a more general overview, focusing mainly on analysing the most important concepts and highlighting the practical aspects of the central environmental principles. This discussion begins with an overview of the general background, the aims of environmental law, and examination of what role environmental factors could play in deciding on cases such as that of the above-mentioned pulp mill. While this particular case has been taken as a starting point for the article and is used as an example here, the paper is not intended to offer a thorough analysis of the matter of the pulp mill, especially since the circumstances of the case are still largely unclear.

4 See http://arileht.delfi.ee/news/uudised/liiga-janune-miljarditehas-pole-sugugi-ahvatlev-pruut?id=78093738, in Estonian (most recently accessed on 25 June 2018).

5 R. Desgagne. Integrating environmental values into the European Convention on Human Rights. - American Journal of International Law 89 (1995) / 2, pp. 263-294, on p. 267. - DOI: https://doi.org/10.2307/2204204; J. Lee. The underlying legal theory to support a well-defined human right to a healthy environment as a principle of customary international law. - Columbia Journal of Environmental Law 25 (2000), pp. 283-340.

6 See H. Veinla, S. Vahtrus. Substantive environmental right in Estonia - basis for citizens' enforcement. - Nordic Environmental Law Journal 2016/3, pp. 7-21. 


\section{The aims of legal regulation in the environmental field}

It is worth starting the analysis of cases such as the proposed pulp mill's from the perspective of the aims behind environmental law, since environmental law is concerned not only with the legal benefits offered by the environment but also with finding optimal solutions.

The aims of environmental law in Estonia are stipulated in the General Part of the Environmental Code Act $^{*} 7$ (hereinafter GPECA). It has to be taken into account that the aims stated in this law are not only declarations but legally binding for the parties implementing the law. Therefore, a legal measure should facilitate the process of reaching these goals or at the very least not hinder it. ${ }^{* 8}$ There is broad scope for discretion in this case, since the statement of aims does not dictate specific measures; however, if a certain legal measure is clearly necessary for reaching a certain goal, this measure needs to be implemented - for example, refusing to issue a permit for projects that cause significant environmental nuisances, particularly if the planned activities are not justified by any other imperative interests or by there not being any other alternatives.

The first item in $\S 1$ of the GPECA states that the aim of this act of law is reduction of environmental nuisances to the greatest extent possible, so as to protect the environment and human health, well-being, property, and cultural heritage. Therefore, the Estonian environmental law is not radically 'green': the aim is not to fully and unconditionally avoid environmental nuisances, since, regrettably, functional human society and increasing our prosperity are not possible without certain negative impacts on the environment. The existence of individuals and the society they form always entails some level of negative effects on the environment - it is not possible to avoid these utterly. At the same time, the principle of a high level of environmental protection must not be forgotten. This principle does not entail automatically giving priority to the economic and social interests that exist in competition with environmental interests. In the context of the example case considered here, this means that, irrespective of the great economic and social gains associated with the pulp mill, environmental considerations (including those related to ecosystem services) must not be disregarded, let alone ignored. When one is assessing environmental impacts, the various characteristics, probability levels, and possible consequences need to be taken into account. Therefore, in the discussion below, we must expand upon the concept of environmental nuisance - which is central in the domain of environmental law - along with the other structural elements of environmental law associated with this concept.

\section{The ways in which an environmental impact can manifest itself}

With the entry into force of the GPECA, the concept of environmental nuisance and its consequences first appeared in Estonian environmental law. ${ }^{*}$ Since environmental law is aimed mainly at protecting basic rights related to the environment and because one of its core goals is the preservation of humans' health, along with their mental and physical well-being, it is to be emphasised that the concept of environmental nuisance also encompasses the effects on human health, welfare, and property that present themselves in relation to the environment. An adverse impact can be understood also as an effect that, while not in itself harming human health, causes significant direct or indirect physical or mental discomfort. One example would be loud noise or foul odours emanating from the pulp mill that impinge on people enjoying their homes. An adverse environmental impact could have a direct or indirect influence on, among other elements, an individual's property. For example, property might become polluted by dangerous substances

Adopted on 16.2.2011. RT I, 28.2.2011, 1.

8 A. Epiney. Environmental principles. - R. Macrory (ed.). Reflections on 30 Years of EU Environmental Law: A High Level of Protection? Groningen, Netherlands: Europa Law Publishing 2006, pp. 5-6.

9 Subsection 3(1) of the GPECA states: "Environmental nuisance" means a human-induced direct or indirect adverse impact on the environment, including impact on human health, well-being, property or cultural heritage via the environment. "Environmental nuisance" also [encompasses] an adverse impact on the environment [that] does not exceed a numerical limit or that has not been regulated by a numerical limit.' 
(waste and others), or the market value of land could decrease in consequence of noisy surroundings. In the case of the pulp mill and many similar projects, all of these impacts are likely.

While the key concept connected with environmental nuisances includes the evaluative term 'adverse', the law does not actually elucidate which environmental nuisances may unconditionally be inflicted, which need to be reduced, and which are to be prevented. As is alluded to above, many environmental nuisances are necessary for society's functioning and hence have to be tolerated. Any kind of production entails adverse effects on the environment to some extent - this is inevitable. And it is impossible to achieve human well-being without production. This does not, however, mean that we should refrain from trying to implement reasonable measures to reduce and limit the adverse impacts of these necessary activities. As is noted above, to some extent environmental nuisances need to be tolerated if their reduction cannot be accomplished by reasonable measures, the impact of the nuisance on the environment and the individual is insignificant, or the nuisance needs to be tolerated because of some overriding interest that cannot be addressed by any other reasonable means.

It is worth keeping in mind the principle set forth in the GPECA's Section 11 (2) by which in the course of making decisions related to activities entailing environmental risk, the impact of said activities on the environment shall be determined. It is necessary to conduct environmental impact assessment proceedings in the cases specified in the law, with these proceedings being handled in the manner stipulated by law. The principle of economical use of natural resources, which is recognised in international, EU, and Estonian environmental policy and law, means in its classical interpretation that deliberations over all actions shall take environmental factors into consideration in addition to economic and social elements. Ignoring environment-related requirements when dealing with plans and activities that entail significant environmental impact can be a serious error. That error may have legal consequences, and in extreme cases the relevant administrative act may even be declared void. Accordingly, economic aspects manifestly do not automatically have unconditional superiority.

\section{Differentiating between environmental risks and environmental hazards and between the precautionary and the preventive principle}

One of the main concerns with respect to plans and activities with a supposed adverse environmental impact is whether the planned activity could cause environmental hazards in addition to environmental risks and, consequently, whether the precautionary principle or instead the preventive principle should be applied.

\subsection{Environmental risks and the precautionary principle}

Section 4 of the GPECA defines the concept of an environmental risk. The meaning of this concept in environmental law differs from the general understanding of the term. Risk usually means undesired consequence (including harm) that has some likelihood of arising from a given decision or activity. The legal sense expands upon this. In the GPECA, there are two dimensions to an environmental risk: the consequence's seriousness and the probability of its realisation.' This could, however, be seen as a non-lawspecific distinction, since, for instance, risk-analysis matrices address both dimensions. According to the GPECA, an environmental risk exemplifies a situation in which, firstly, it is possible for an adverse impact to occur and, secondly, this consequence needs to be reduced. Determining which environmental risks need to be reduced is largely a value judgement, which is to be made by the legislator. Since environmental law is greatly influenced by EU law, this obligation may arise as a result of transposition of EU law.

For a better understanding of the concept of an environmental risk, comparison to the concept of an environmental hazard (discussed explicitly below) is worthwhile. The notion of environmental risk, outlined above, is applicable in situations wherein at least one of these fundamental characteristics of an environmental hazard is not present: meeting a threshold of probability of the consequence occurring and the environmental nuisance exceeding a certain level of significance. In other words, the concept of an 
environmental risk is applied for situations in which there is not a great enough possibility of a significant enough environmental nuisance occurring - i.e., in which the two criteria for an environmental hazard are not both met. Accordingly, a situation in which the consequence is not highly significant (or there is a less substantial environmental nuisance) can be described as involving an environmental risk rather than hazard even if its occurrence is likely. ${ }^{*} 10$

For appropriate identification of an environmental risk, it is important, as a rule, to follow what is stipulated by acts of law. However, this is not enough. With regard to case-by-case application, it is necessary to take into consideration also the objective evaluation of the circumstances of each individual case, along with the various interests and rights. This process should be based additionally on prior experience and practice related to the possible consequences and their likelihood. Ignoring even the less intense nuisances or not making a reasonable attempt to reduce the adverse effects of a nuisance is not justified. At this point in the discussion, it is relevant to refer to the GPECA's §14, which deals with the general obligation of diligence, stipulating in this connection that everyone has to take measures to reduce the environmental nuisances caused by his or her actions or inaction, as far as can reasonably be expected.

It follows from the GPECA's $\S 11$ that in cases of environmental risk, one is to apply the precautionary principle, which has now become one of the foundations of environmental law internationally, in the EU, and within many individual countries. Historically, the main reason for the emergence of the precautionary principle is disappointment in the so-called assimilative capacity approach, a theory that was based on the assumption that contemporary science is capable of ascertaining and actively predicting the 'safe' level of use of the relevant elements of the environment, accurately ascertaining the negative environmental impact of a given activity, and developing technical solutions for preventing negative impacts. It became clear in practice that science cannot, in fact, unequivocally predict the consequences of human activity. The classical legal approach does not justify taking measures to limit the rights and freedoms of individuals in such situations of uncertainty. The ushering in of the precautionary principle, in contrast, represents a dramatic change in approach, allowing (or even demanding) that measures be taken to reduce environmental risks even in uncertain situations ${ }^{* 11}$. In conclusion, notwithstanding the fact that in cases such as the pulp mill's not all adverse impacts are obvious and many remain shrouded in scientific uncertainty, it is necessary to apply reasonable measures for purposes of reducing environmental risks.

The GPECA adds a new dimension to the classical interpretation of the precautionary principle by which the principle is tied in with scientific uncertainty. The GPECA stipulates that, in addition to cases of scientific uncertainty, the precautionary principle applies in situations in which either of the two criteria for an environmental hazard is not met. In these cases, it is necessary to take reasonable measures to reduce adverse environmental nuisances. When one is determining the appropriate precautionary measures to choose, it is crucial to consider the principle of proportionality and to ensure that the measures are legitimate, suitable for achieving the aim, and necessary for fulfilling that aim, while at the same time those measures are reasonable in light of the competing interests of the various groups in the case at hand.

The more important the negatively affected legal interest in question and the more probable the impact, the more economically and socially burdensome the measures to reduce adverse impacts are permitted to be.

An approach characteristic of this interpretation of the precautionary principle can be seen in GPECA in the paragraph (§ 16) stipulating an installation operator's general obligations, which assigns the operator the duty to acquire knowledge for the prevention of environmental hazards that may occur in consequence of the functioning of the installation, along with the duty to evaluate these risks and to take appropriate precautionary measures. ${ }^{*}$

10 H. Veinla. Basic structures of the Draft General Part of the Environmental Code Act. - Juridica International 2010/10. pp. 135-136.

11 See E. Fisher. Precaution, precaution everywhere: Developing a 'common understanding' of the precautionary principle in the European Community. - Maastricht Journal of European and Comparative Law 9 (2002) / 1, pp. 7-28, on p. 9. - DOI: https://doi.org/10.1177/1023263x0200900102.

12 H. Veinla, S. Vahtrus. Operators' general obligations as an environmental duty of care. - Juridica International 2013/1, pp. 169-178. 


\subsection{The concepts of significant environmental nuisance, environmental hazard, and the principle of prevention}

As mentioned above, the threshold associated with so-called unacceptable environmental nuisances is the posing of an environmental hazard, which, in turn, is associated with the idea of significant environmental nuisances.

The GPECA defines a significant environmental nuisance as a significant adverse impact on the environment, where the impact may be on human health, well-being, property, or cultural heritage (§2 (2)). In the event of sufficient likelihood of the occurrence of a significant environmental nuisance, the local authorities must follow the prevention principle as stipulated in the GPECA's §10, and under GPECA §16 operators are obliged to take measures actively to prevent significant environmental nuisances. Therefore, if it appears that in cases similar to the pulp mill's the occurrence of not only environmental nuisances but also significant environmental nuisances is likely, decisions must be taken on a completely different basis. Whether significant environmental nuisances actually might occur and the probability of their occurrences must be clarified through environmental impact assessment procedures.

Sufficient likelihood of a significant environmental nuisance occurring is characteristic of situations involving an environmental hazard. Here, 'sufficient likelihood' refers to sufficient certainty of occurrence of the impact. For instance, in the example of exceeding the limit values set in relation to the quality of outside air, it should be presumed that failing to fall within these limits may (i.e., is sufficiently likely to) result in a health hazard. Likewise, there is sufficient likelihood of environmental nuisances occurring in consequence of the production of fossil fuels with current technology, which is one of Estonia's most important industries and also the biggest source of Estonia's environmental burden - producing most of the country's waste, water consumption, and air pollution. In specification of the 'sufficient likelihood' threshold, the principle of integral protection of the environment coupled with a high level of protection needs to be considered. In cases of doubt, this consideration sways the decision towards there being deemed sufficient likelihood of the impact occurring. When the level of certainty in respect of occurrence of the impact is lower, higher priority is given to the protected legal interest, and vice versa - the greater the priority given to the legal interest, the lower the level of certainty.

Thus, the concept of an environmental hazard is applicable to situations in which the environmental nuisance is too intense to be tolerated. According to the prevention principle, explained below, actualisation of an environmental hazard needs to be prevented. One of the main instruments for bringing about the prevention of environmental hazards is environmental protection permits, which specify the conditions for the use of the environment and entail supervision and monitoring. Prevention of an environmental hazard can be regarded as taking place also when measures that reduce the significance and the likelihood of occurrence of the environmental nuisance are taken to such an extent that the environmental hazard is reduced into an environmental risk. That risk, in turn, needs to be reduced by means of further, precautionary measures.

The prevention measures that need to be taken in specific cases are often stipulated from the outset at the level of legislation, but legal acts do not always stipulate the full catalogue of practical applications of the prevention principle. Various cases can be pointed out in respect of concrete prohibitions with their origins in legal norms. For example, it is normally forbidden to convey wastewater into groundwater or convey sewage or wastewater onto frozen soil. Additionally, waste law generally forbids mixing one kind of dangerous waste with other kinds of dangerous waste, regular waste, or any other substance or material. The Estonian outdoor-air protection law emphasises that if the environmental protection permit requires abatement of pollution or it has been specified in the materials for the proposed building project, working without the accordant abatement equipment or with non-functioning abatement equipment is forbidden. Also, the Estonian Conservation Act prohibits all human activity in a nature reserve, including human presence in said territory ( $\$ 29(2))$. Ignoring these prohibitions could indeed have sufficient likelihood of bringing about the occurrence of significant environmental nuisances that it must be addressed.

The prevention principle, as a general principle of environmental law, has to be applied case-specifically, in addition to compliance with detailed legal prohibitions. An example of application of the prevention principle, as it is dependent on discretion, can be found in the regulations in water-related law that constitute the basis for refusal to issue a permit for special use of water in cases wherein the water supply is insufficient, the special use of water directly endangers human health or the environment, or the 
groundwater level or the condition of the groundwater for those fed by it deteriorates to such an extent that the groundwater supply is rendered defunct. Another example of the case-by-case application of the prevention principle would be a situation in which entrepreneurs plan to 'reconstruct' a hog farm (i.e., replace it with a much larger complex) in the immediate vicinity of a settlement and, in so doing, greatly increase the number of pigs there. In the example, people whose home is in the direct vicinity of the farm claim that the planned considerable increase in the number of animals would greatly increase the amount of manure and thereby intensify the odour nuisance, owing to the fact that more manure will be transported and spread over fields. What is more, an odour nuisance is likely to be caused also by the new complex itself. The local authority, on whose approval the construction of the new complex is contingent, might in this case come to the conclusion that, since there are no effective technological solutions for reduction of the odour nuisance, which would clearly and significantly affect the well-being of numerous people, this case can be identified as involving an environmental hazard.

Whilst persons in private law are not the addressees of the prevention principle, an approach in accordance with it can indirectly be carried over to them, chiefly through decisions of local authorities that are based on the prevention principle. An example of this kind of activity would be the procedure related to granting of environmental impact permits, in which the conditions for permits are based on the goal of preventing environmental hazards that could occur as a result of the relevant activity.

An approach incorporating the prevention principle is reflected also in the GPECA's paragraphs on operator obligations, by which everyone, especially the operator, is obliged to obtain knowledge of the environmental hazards related to the planned activity; to evaluate these hazards; and, to a reasonable extent, to take appropriate measures to prevent the realisation of the hazards.

The foregoing notwithstanding, the duty to prevent an adverse environmental impact that exceeds the thresholds for probability and significance is not absolute. Furthermore, the duty of tolerance applies with regard to hazards that have already been realised - that is, significant environmental nuisances that have already arisen. As is stated in the GPECA's §10, an environmental hazard or a significant environmental nuisance must be tolerated under the following three conditions:

- the activity being necessary for reason of a dominant interest

- there being no reasonable alternatives to secure this interest

- the necessary measures having been taken to reduce the environmental hazard or significant environmental nuisance

In cases such as that of the proposed pulp mill, the first and second condition above seem to be, at least theoretically, fulfilled. The assumed large economic gain from the activity and creation of a considerable number of jobs give reason to think that an interest outweighing the negative environmental impact could exist. However, a closer look reveals that the fulfilment of the second condition is problematic. It is difficult to find convincing arguments supporting the claim that the additional economic and social gain could be achieved only through construction of the proposed pulp mill, in this particular location and with this particular capacity. Surely there are reasonable alternatives. Furthermore, it should be noted that in the process of considering alternatives the greatest emphasis should be on public interests instead of the capacity and interests of the developers. On account of such considerations, in a situation in which activity brings about environmental hazards, the conditions for making exceptions are to be interpreted narrowly.

\section{Conclusions}

It is obvious that almost all human activity, not to mention large-scale economic production in particular, causes environmental impacts to some extent. The impact can vary greatly in its intensity, consequences, and probability. Accordingly, such variability needs to be taken into account in the process of finding legal solutions to economic, social, and environmental conflicts. Environmental legislation does not rule out production and development activities but can significantly limit these and, through its restrictions, guide towards socio-ecological sustainability ${ }^{*}{ }^{13}$.

Controlling environmental nuisances is central to regulations in environmental law. The first step articulated in regulation of environmental nuisances is to research and evaluate the impacts that the proposed

13 See C. Azar et al. Socio-ecological indicators for sustainability. - Ecological Economics 18 (1996) / 2 (August), pp. 89-112. DOI: https://doi.org/10.1016/0921-8009(96)00028-6. 
activity or plan may have on the environment and human health, well-being, and property. In most cases, this is done through formal proceedings based on the terms of an environmental assessment law. In Estonia, even where conducting these proceedings is not mandatory, according to GPECA ( $\$ 11$ (2)), when one is making decisions about activities with a possibility of causing environmental risks, it is necessary to employ some other, non-formalised way of obtaining knowledge about what kind of environmental impact the activity is going to have.

Proven or assumed environmental nuisances caused by the activity in question do not necessarily need to be reduced or prevented; this duty applies only when a higher threshold is crossed - that is, when the environmental risk and/or hazard limit is exceeded. Hence, in cases such as that of the pulp mill, it has to be established whether the proposed activity will actually cause environmental risks and/or hazards. In the case of environmental risks (i.e., in situations in which it is possible for an environmental nuisance that needs to be reduced to occur), the goal is not a priori prohibition of the activity but the application of measures that reduce the risk proportionally, where those measures might be carried out by such means as attaching additional conditions to environmental permits. Once the measures are set forth, it is up to the operator to decide whether meeting the prescribed conditions is feasible or, instead, the planned activity would be economically unreasonable under those conditions. The occurrence of environmental risks is highly likely in the case of the pulp mill, which means that the need for application of the precautionary principle is highly probable.

Also, the likelihood of significant environmental nuisances (environmental hazards) occurring in relation to the planned activity is potentially great in the example case of the pulp mill. Reference has been made to possible pollution: the direct or indirect discharge or disposal, as a result of human activity, of substances or energy into the air, water, or soil to such an extent that harm to human health, living resources, and ecosystems occurs. When the probability of pollution occurring is deemed to be great enough, there is deemed to be an environmental hazard, which must be prevented. Whether a hazard exists or not must be revealed in the course of further (scientific) research. That said, an environmental hazard or a significant environmental nuisance needs to be tolerated in cases wherein all three of the following conditions are fulfilled: the activity is rendered necessary by a dominant interest, there are no reasonable alternatives to safeguard this interest, and the necessary measures have been taken to reduce the environmental hazard or significant environmental nuisance. The fulfilment of the first and the second condition is possible in the case of the pulp mill. However, the second condition, in fact, seems not to have been met after all, since there may exist alternatives. That said, the issue of the existence of alternatives is a complex and separate topic, one that is not within the scope of this article. For example, when one is assessing alternatives, the following are among the main problems encountered: what role similarity of socio-economic and technical characteristics plays and how cost-benefit analyses for various possible alternatives (variant designs etc.) can be handled.

As has been noted, the construction of the pulp mill is possible on the condition that the occurrence of an environmental hazard is prevented. If this cannot be done, issuing a permit for the mill does not seem possible under the law in force. The permit would have to be granted exceptionally; however, the conditions for making an exception are not fulfilled. 